\title{
Effect of storage time on physicochemical, sensorial, and antioxidant characteristics, and composition of mango (cv. Azúcar) juice
}

\author{
Maria Bibiana Zapata Londoño1, Diana Chaparro', Benjamin Alberto Rojano², \\ Andres Felipe Alzate Arbelaez ${ }^{2}$, Luis Fernando Restrepo Betancur ${ }^{3}$, Maria Elena Maldonado Celis ${ }^{1}$
}

${ }^{1}$ Grupo ICAS, Escuela de Nutrición y dietética, Universidad de Antioquia, Medellín-Colombia, ${ }^{2}$ Grupo Química de los productos naturales y los alimentos, Facultad de Ciencias, Universidad Nacional de Colombia, sede Medellín, Colombia, ${ }^{3}$ Grupo GISER, Facultad de Ciencias Agrarias,

Universidad de Antioquia, Medellín-Colombia

\section{A B S T R A C T}

\begin{abstract}
Mango is one of the most popular fruits and a good source of antioxidants compounds. In this study, we monitor the stability of physicochemical and sensory characteristics, antioxidant activity and content of carotenoids and polyphenols of ripe mango cultivar Azúcar stored up to 60 days at $-20^{\circ} \mathrm{C}$. All analyses were carried out in mango juice prepared using pulp stored during $1,8,30,44$ and 60 days. The sensory analysis was carried out by 200 untrained panelists and juices B and D had the highest scores in all attributes followed by juice C. Physicochemical characteristics were measured by official methods (Association of official analytical chemists) and they were similar through different storage time except for calories and total carbohydrates. Total carotenoids, flavonoids and polyphenols content were measured by colorimetric methods. Polyphenols content was similar over time, meanwhile carotenoids and flavonoids content increased after 8 days of storage and they decreased after 30 days of storage. Antioxidant activity was measured by DPPH (2,2-diphenyl-1-picrylhydrazyl) radical, ABTS (2,2'-azino-bis-3-ethylbenzthiazoline-6-sulfonic acid) radical and hydrophilic ORAC (oxygen radical absorbance capacity) method. Juice prepared after 8 and 30 days of mango storage showed the highest antioxidant activity in almost methods. In conclusion, juice prepared from ripe mango cultivar Azucar had similar physicochemical characteristics, sensory characteristics, total phenolic content and antioxidant activity between 1 and 30 days of storage at $-20^{\circ} \mathrm{C}$.
\end{abstract}

Keywords: Azucar; Antioxidant; Carotenoids; Mango juice; Polyphenols.

\section{INTRODUCTION}

Mango (Mangifera indica L.) is the second largest crop and one of the most important tropical fruits due to its popularity and high production. It is cultivated in several tropical and subtropical countries in Asia, Africa and America (Liu et al., 2014).

Mango is consumed as a fresh fruit as well as a processed product like juice, pulp, powder, mash, pickles and syrup (Liu et al., 2014) and among these products, juice has the higher consumption. Fruit juices market has increased considerably as consumers have become more concerned with healthier lifestyles, therefore consumption of mango juice represents an alternative strategy for attaining the dietary recommendations for fruit consumption (Kaur and Kapoor, 2001; Renuka et al., 2009).

Mango is considered as a good source of dietary antioxidant compounds such as carotenoids, polyphenols and ascorbic acid (Kaur and Kapoor, 2001), therefore mango consumption could be useful to prevent chronic diseases relate with oxidative stress such as cardiovascular disease, cancer and neurodegenerative diseases (Bagchi et al., 2000).

Over 1000 cultivars have been identified around the world (Krenek et al., 2014), such as Tommy, Keitt, Haden, Ataulfo, Tainong, Azucar and Irwin which have shown antioxidant activity (Ma et al., 2011; Manthey and PerkinsVeazie, 2009; Corrales-Bernal et al., 2014a).

\footnotetext{
${ }^{*}$ Corresponding author:

Maria Elena Maldonado Celis, Grupo ICAS, Escuela de Nutrición y dietética, Universidad de Antioquia, Medellín-Colombia.

Tel.: (+574) 2199223. E-mail: maria.maldonado@udea.edu.co
}

Received: 21 September 2016;

Revised: 25 February 2017;

Accepted: 02 March 2017;

Published Online: 12 March 2017 
Mango pulp is used to prepare juice after several days of storage at different temperatures by consumers (Liu et al., 2014) so it is important to consider which temperature is the best option to keep its quality (Robles-Sanchez et al., 2009; Kim et al., 2007). Storage at room temperature can affect its composition and flavor due to the action of microorganisms and enzymes, consequently, in order to prevent those changes, different methods such as pasteurization and storage under frozen temperatures have been used (Kim et al., 2007). These methods inactivate enzymes and decrease or eliminate microorganisms which extend the shelf life of the pulp however, they can affect sensory attributes, antioxidant activity and biochemical characteristics in the mango pulp such as carotenoids and phenolic compounds (Hossain et al., 2014).

There are not reports about changes in sensory characteristics of mango (cultivar Azúcar) pulp subjected to pasteurization followed by storage under freeze temperatures thus carrying out a sensory analysis is important because it could detect modifications in the perception of the product attributes (Da Silva et al., 2014).

Previous studies showed that the pulp from mango cultivar Azúcar contained significant amounts of polyphenols and carotenoids and it had antioxidant activity in vitro assessed by DPPH• (Corrales-Bernal et al., 2014a); however, there is no information about changes in polyphenols content, carotenoids content or antioxidant activity in mango cultivar Azucar during storage. Therefore, the purpose of this study was to monitor the stability of antioxidant activity, content of polyphenols, carotenoids and flavonoids of juice prepared with mango (cv. Azucar) stored up to 60 days at $-20^{\circ} \mathrm{C}$.

\section{MATERIALS AND METHODS}

\section{Raw material}

Mature mango (cv. Azucar) were obtained from a supplier from the Colombian Caribbean coast out of a local market in Medellin, Colombia in June 2015 and they were identified by local farmers. Mango ripened after storage at $25^{\circ} \mathrm{C}$.

Ripeness degree was determined according to the following criteria: peel colour, firmness and flavor based on Colombian Technical Standard 5139 (Instituto Colombiano de Normas técnicas y certificación ICONTEC, 2004). Ripe mango was immersed in a solution of sodium hypochlorite (100 ppm), washed with water, peeled, cut into small pieces, packed in plastic bags and immediately frozen at $-20^{\circ} \mathrm{C}$ until use.

\section{Juice preparation}

Mango juice was prepared from peeled mango pieces after 0 (A), 8 (B), 30 (C), 44 (D) and 60 (E) days at $-20^{\circ} \mathrm{C}$.
The juice was prepared mixing mango pieces and water $(1: 4)$ and the final total solids were measured by a refractometer at $20^{\circ} \mathrm{C}$ and different quantities of sucrose were added to assure Brix degrees between $12^{\circ}$ and $14^{\circ}$. Then, juice was sweetened with $1 \mathrm{~g}$ of sucralose, pasteurized at $85^{\circ} \mathrm{C}$ for $10 \mathrm{~min}$, filled in $200 \mathrm{ml}$ sterile and plastic bottles which were rapidly cooled by immersing them in a cold water bath. Gelatin $(0.07 \% \mathrm{w} / \mathrm{w})$ was used as stabilizer.

\section{Microbiological analysis}

Colony counts of Escherichia coli and total coliforms was carried out by most-Probable-Number (MPN) method according to Food and Drug Administration's Bacteriological Analytical Manual (1998). Aerobic mesophilic bacteria, yeasts and molds were counted by agar plaque technique according to Colombian Technical Standard 4458 (Instituto Colombiano de Normas técnicas y certificación ICONTEC, 2007). The results were expressed as colony forming unit (CFU). The analysis was done taiking into account the requirements of Colombian Institute of Surveillance of drugs and Foods (INVIMA) for fruit juices.

\section{Physicochemical analysis}

Moisture, total fat, minerals and total proteins were measured according to methods of Association of Official Analytical Chemists (AOAC) and total calories and carbohydrates were calculated based on mango components.

\section{Sensory analysis}

Sensory evaluation was carried out by 200 untrained panelists recruited from "Universidad de Antioquia" and $20 \mathrm{~mL}$ of mango juice was presented in plastic cups.

The evaluations were performed using a 3-point hedonic scale ranging from 1 to 3 (1- to like, 2- neither like or dislike and 3 - not to like). The attributes color, texture, odor, sweetness, flavor and overall acceptability of juice were evaluated by all panelists.

\section{Total phenolic content}

The total phenolic content was determined according to a modified Folin-Ciocalteu described by Prior et al. (2005). The juice $(10 \mu \mathrm{L})$ was mixed with $125 \mu \mathrm{L}$ of FolinCiocalteu reagent and $400 \mu \mathrm{L}$ of sodium carbonate solution $(7.1 \% \mathrm{w} / \mathrm{v})$, and the resulting solution was brought up to a final volume of $1000 \mu \mathrm{L}$. The mixture was incubated at room temperature for $30 \mathrm{~min}$ in the dark. The absorbance was measured at $760 \mathrm{~nm}$ against a blank. Standard solution of gallic acid was used to perform calibration curves. The results were expressed as $\mathrm{mg}$ of gallic acid equivalents $(\mathrm{GAE}) / \mathrm{L}$. 


\section{Total flavonoids content}

The flavonoids were determined by colorimetric method described by Marinova et al. (2005). $100 \mu \mathrm{L}$ of juice were mixed with $30 \mu \mathrm{L}$ of $\mathrm{NaNO}_{2}(5 \% \mathrm{w} / \mathrm{v}), 30 \mu \mathrm{L}$ of $\mathrm{AlCl}_{3}(10 \% \mathrm{w} / \mathrm{v}), 200 \mu \mathrm{L}$ of $\mathrm{NaOH}(1 \mathrm{M})$, and the resulting solution was brought up to a final volume of $1000 \mu \mathrm{L}$ with distilled water. The absorbance was measured at $510 \mathrm{~nm}$. $(+)$-Catechin standard solution was used to perform the calibration curves and the results were expressed as catechin equivalents/L.

\section{Total carotenoids content}

The juice was mixed with $4 \mathrm{ml}$ of acetone, incubated at $4^{\circ} \mathrm{C}$ for $15 \mathrm{~min}$, agitated with a vortex mixer (scientific industries) and centrifuged at $4000 \mathrm{rpm}$ for $10 \mathrm{~min}$. The supernatant was collected and transferred to a tube. The precipitate was mixed with $4 \mathrm{~mL}$ of acetone and the procedure described above was repeated. Both extracts were combined and filtered through a $2.5 \mu \mathrm{m}$ paper filter. Finally, the absorbance was measured at $449 \mathrm{~nm}$. $\beta$-Carotene standard solution was used to perform the calibration curves and the results were expressed as $\mathrm{mg}$ $\beta$-carotene/L (Biswas et al., 2011).

\section{Antioxidant activity determined by DPPH• assay}

Modified Brand-Williams et al. (1995) method described by Puertas-Mejia et al. (2005) was carried out to measure radical scavenging activity of mango juice against the stable radical DPPH・ (2,2- diphenyl-1-picryl hydrazyl). Briefly, $10 \mathrm{~mL}$ of juice was incubated with $990 \mathrm{~mL}$ of $\mathrm{DPPH} \bullet$ in a methanol solution for $30 \mathrm{~min}$ at room temperature. A standard curve was performed using Trolox and the results were expressed as $\mu \mathrm{M}$ Trolox/L. The absorbance was determined at $517 \mathrm{~nm}$.

\section{Antioxidant activity determined by hydrophilic ORAC (oxygen radical absorbance capacity) assay}

The hydrophilic ORAC (ORAC-H) assay was performed as described by Ou et al. (2001). Briefly, the working solution was prepared by mixing $21 \mu \mathrm{L}$ of $10 \mu \mathrm{M}$ fluorescein solution, $2899 \mu \mathrm{L}$ of $75 \mathrm{mM}$ phosphate buffer (pH 7.4), $50 \mu \mathrm{L}$ of $600 \mathrm{mM} \mathrm{2,2'-Azobis}$ (2-methylpropionamidine) dihydrochloride (AAPH) and $30 \mu \mathrm{L}$ of juice. Fluorescence was measured on a Perkin Elmer LS45 spectrofluorometer with a thermostatted multicell. The results were expressed as $\mu \mathrm{M}$ trolox/L, according to the following Equation:

$$
\mathrm{OR} A C=\frac{\left(A U C-A U C^{\circ}\right)}{\left(A U C_{\text {Trolex }}-A U C^{\circ}\right)} f[\text { Trolex }]
$$

where AUC is the area under the curve of the sample, $\mathrm{AUC}^{\circ}$ is the area under the curve for the control, AUC Trolox is the area under the curve for Trolox and $\mathrm{f}$ is the dilution factor for juice (Romero et al., 2010).

\section{Antioxidant activity determined by ABTS ${ }^{+}$assay}

ABTS $^{++}$(2,2'-azino-bis-3-ethylbenzthiazoline-6-sulfonic acid) assay was performed as described by Re et al. (1999). Briefly, $10 \mu \mathrm{L}$ of juice were added to $990 \mu \mathrm{L}$ of diluted $\mathrm{ABTS}^{*+}$ in ethanol, and the resulting solution was incubated at room temperature for $30 \mathrm{~min}$ in the dark. The absorbance was measured at $734 \mathrm{~nm}$ against a blank. Trolox standard solution was used to perform the calibration curves and the results were expressed as $\mu \mathrm{M}$ Trolox $/ \mathrm{L}$.

\section{Statistical analysis}

Unidimensional exploratory descriptive analysis was carried out to calculate arithmetic mean, standard deviation and variation coefficient.

Assays to measure antioxidant activity were conducted by triplicate and data were reported as the mean \pm standard deviation (SD). The differences between groups were estimated by one-way analysis of variance (ANOVA) followed by Tukey's post-hoc test. A value of $p<0.05$ was considered statistically significant.

Data from sensory profile were analyzed using Multivariate analysis of variance (MANOVA) through GLM (General Linear Model) procedure with canonical orthogonal contrast. The dimensionality of multidimensional comparison was determined by maximum likelihood in order to find the highest significant value related with contrast dimensionality that allowed to carry out comparison between different juices and scores of sensory attributes whether they are related or not to gender and age of the panelists. In addition, a factor analysis by principal component method and Chisquare was carried out to evaluate the product acceptance with respect to the evaluated attributes. A value of $\mathrm{p}<0.05$ was considered statistically significant.

The results were analyzed using the statistical package SAS University.

\section{RESULTS}

\section{Microbiological and physicochemical analysis}

All juices fulfilled the requirements from INVIMA for fruit juice regarding microbial load and count of yeasts and molds. The count of E. coli, total coliforms, and aerobic mesophilic bacteria were low, corresponding to $<10 \mathrm{UFC} / \mathrm{ml}$ in all juices. Also, the count of yeasts and molds were $<100 \mathrm{UFC} / \mathrm{ml}$ in all samples (data not shown).

To prepare juice from mango pulp at different storage time, different amounts of sugar were used to yield a Brix degrees ( ${ }^{\circ}$ Brix) between 12 and $14^{\circ}$ (Table 1). ${ }^{\circ}$ Brix was measured in the juices. The juice $\mathrm{B}$ required the highest amount of sugar to yield the ${ }^{\circ} \mathrm{Brix}$ required (Table 1). The 
percentage of fruit, sucralose and water was the same in all juices.

The results from physicochemical analyses are presented in Table 2. The percentage of moisture, total minerals, total fat and total protein were similar between the different juices. The calories content was low in all juices. Total carbohydrates and total calories showed changes between different juices; juice $A$ showed the lowest percentage of carbohydrates $(7.22 \%)$ and total calories $(29.67 \mathrm{Kcal} / 100 \mathrm{~g})$ in contrast with juice $\mathrm{D}$ which showed the highest content of carbohydrates $(13.43 \%)$ and total calories $(54.67 \mathrm{Kcal} / 100 \mathrm{~g})$. The mean of $\mathrm{pH}$ of all juices was 4.04 (data not shown).

\section{Sensory evaluation}

Five sensory analyses were carried out with 200 untrained men and women as untrained panelists for each time of analysis. The percentage of men in the first, second, third, fourth and fifth analyses was 43.8\%, 48.5\%, 46.7\%, 51.2\% and $48.5 \%$, respectively. The panelists were between the ages of 17 - 78 and most of them belonged to the group age of 17-25 years old. The percentage of panelists belonged to the group age of $17-25$ years old were $85.5 \%, 65.4 \%, 85.6 \%$, $78.5 \%$ and $43.5 \%$ in the in the first, second, third, fourth and fifth sensory analyses, respectively (data not shown).

The percentage of scores given to each attribute of juices by gender is shown in Figs. 1 and 2. The juices B and D had the highest percentage of acceptance for all attributes (color, texture, odor, sweetness and flavor) for both genders and the attribute with the highest score was color. In contrast, the attributes of juice A had the lowest acceptance for both genders and the attribute with the lowest score was sweetness.

Juices B and D had the highest overall acceptability, corresponding to $98.5 \%$ and $96 \%$ for both genders, respectively. The overall acceptability of juices $A, C$ and $\mathrm{D}$ was between $80 \%$ and $90 \%$ (data not shown).

Table 1: Sucrose content and ${ }^{\circ} \mathrm{Brix}$ of the mango juices analyzed

\begin{tabular}{lccc}
\hline $\begin{array}{l}\text { Pulp mango storage } \\
\text { time at }-20^{\circ} \mathbf{C} \text { (days) }\end{array}$ & Juice code & Brix $\left(^{\circ}\right)$ & Sucrose $(\mathbf{g})$ \\
\hline 0 & A & 12 & 180 \\
8 & B & 12 & 506 \\
30 & C & 13 & 669 \\
44 & D & 12.8 & 442 \\
60 & E & 12 & 351 \\
\hline
\end{tabular}

Chi-square test allowed comparing the acceptance of the juices by gender and age regarding different attributes. The acceptance of juice A was related with all attributes (color, texture, odor, sweetness and flavor) for both genders except for texture in men.

The acceptance of juice B was related to flavor, sweetness and texture for women on the contrary, none of the attributes were related to acceptance for men (Table 3). The acceptance of juice $\mathrm{C}$ was related to flavor in both genders and the acceptance of juices $C$ and $D$ was related to flavor, sweetness and texture for both genders and to odor for women (Table 3).

Principal components analyses showed that both genders identified different attributes among juices. Men identified the highest number of attributes in juices $\mathrm{C}$ and $\mathrm{E}$, corresponding to odor, flavor, sweetness, and texture in factor 1 and in factor 2; men identified color in juice B, flavor, odor in factor 1 and texture in factor 2 ; in juice $\mathrm{D}$ men identified flavor and sweetness in factor 1 and color in factor 2 (Table 4).

Women identified all attributes in juice $\mathrm{D}$ in factor 1 and they identified all attributes in juice E except for color; in juice $\mathrm{B}$ women identified odor, color and flavor in factor 1 and texture in factor 2. Therefore, women identified color in all juices in factor 2 except for juice D (Table 5).

In addition, a MANOVA was carried out to evaluate the relationship between acceptance of all attributes for gender or juices (Table 5). The perception of attributes didn't show significant differences between men and women, which indicates that the overall taste of the panelists was similar in both sexes. However, the perception of attributes and the different juices didn't show significant differences (Table 6). The perception of color in juice A did not show significant differences in comparison with the other juices, on the contrary the perception of sweetness showed significant differences in all juices. The perception of attributes between juices B, C and D did not show significant differences.

\section{Total phenolic content}

Total phenolic content was quite stable during storage among the five juices (Table 7) and it didn't show significant differences between them. Total phenolic content was within a range of 155.47 - $124.35 \mathrm{mg}$ GAE/L.

Table 2: Physicochemical properties of mango juices

\begin{tabular}{lcccccc}
\hline Code & Moisture (\%) & Total minerals (\%) & Total fat (\%) & Total protein (\%) & Total carbohydrates (\%) & Total calories (Kcal/100 g) \\
\hline A & 92.55 & 0.06 & 0.02 & 0.15 & 7.22 & 29.67 \\
B & 88.32 & 0.04 & 0.0 & 0.19 & 11.45 & 46.56 \\
C & 89.37 & 0.08 & 0.1 & 0.17 & 10.38 & 42.18 \\
D & 86.32 & 0.05 & 0.03 & 0.17 & 13.43 & 54.67 \\
E & 90.24 & 0.10 & 0.0 & 0.14 & 9.52 & 38.64 \\
\hline
\end{tabular}




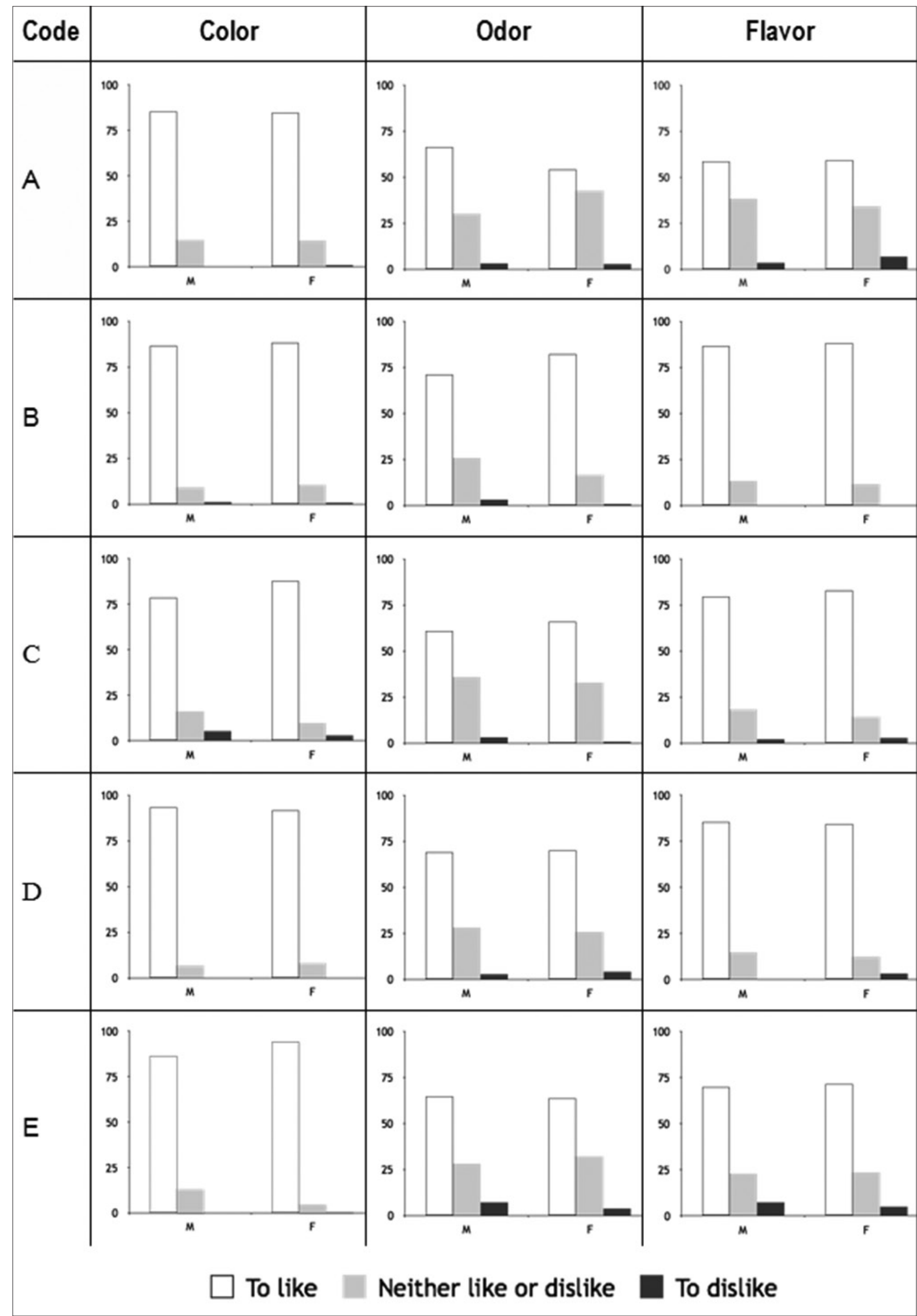

Fig 1. Pulp storage time influence panelists' perceptions of color, odor and flavor; results are expressed as percentage. 


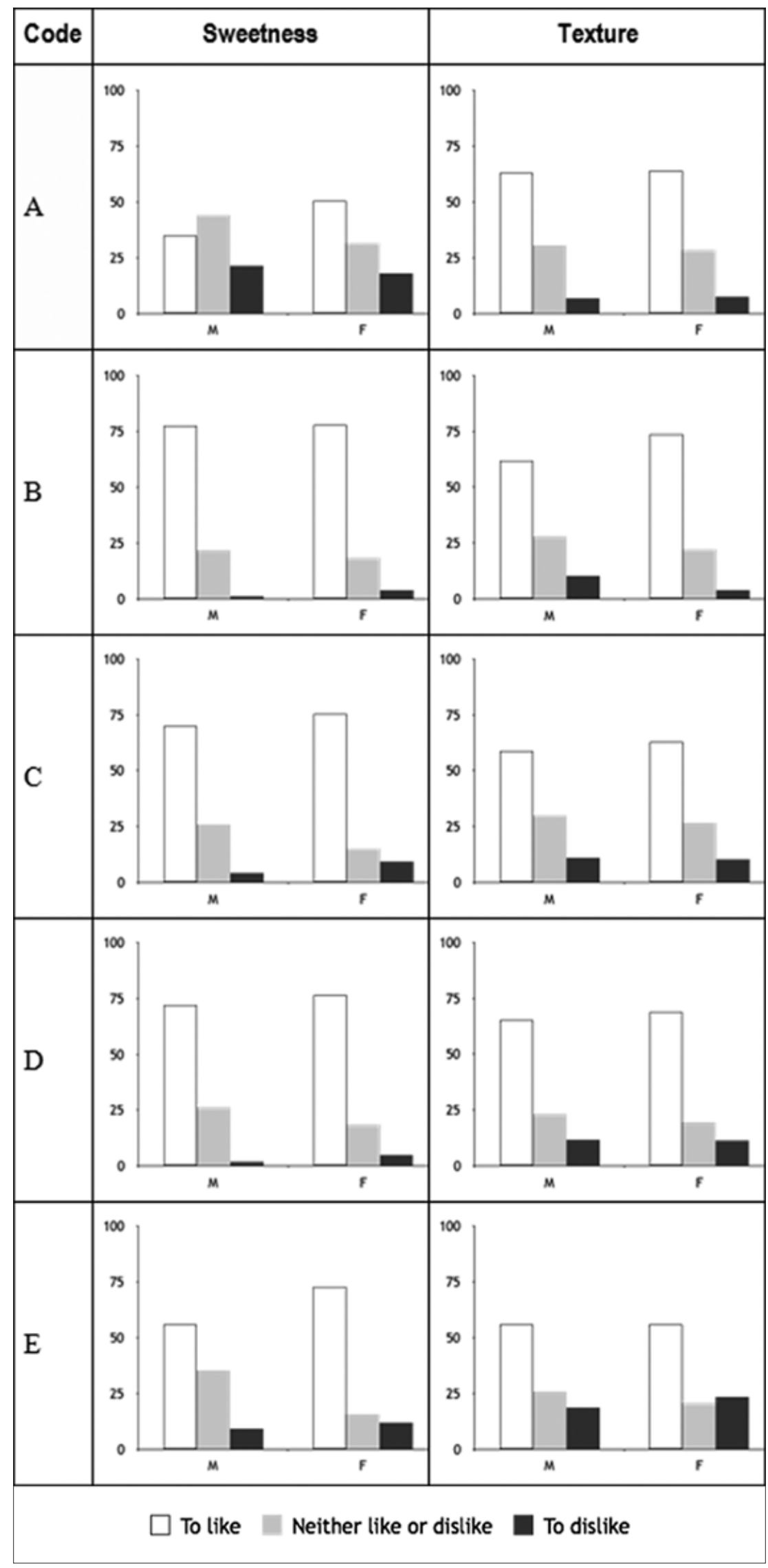

Fig 2. Pulp storage time influence panelists' perceptions of sweetness and texture; results are expressed as percentage. 
Table 3: Relationship of overall acceptance of juices with all attributes by gender

\begin{tabular}{|c|c|c|c|c|c|c|c|c|c|c|}
\hline \multirow{2}{*}{$\begin{array}{l}\text { Attributes } \\
\text { Gender }\end{array}$} & \multicolumn{2}{|c|}{ Color } & \multicolumn{2}{|c|}{ Odor } & \multicolumn{2}{|c|}{ Flavor } & \multicolumn{2}{|c|}{ Sweetness } & \multicolumn{2}{|c|}{ Texture } \\
\hline & $\mathbf{M}^{\mathrm{a}}$ & $F^{b}$ & $\mathbf{M}$ & $\mathbf{F}$ & M & $\mathbf{F}$ & M & $\mathbf{F}$ & M & $\mathbf{F}$ \\
\hline \multicolumn{11}{|l|}{ Code } \\
\hline$A$ & 0,0158 & $<0,0001$ & 0,0016 & 0,0007 & $<0,0001$ & $<0,0001$ & 0,0056 & $<0,0001$ & 0,1209 & 0,0021 \\
\hline B & 0,8893 & 0,9349 & 0,7202 & 0,0849 & 0,1247 & 0,0059 & 0,6138 & $<0,0001$ & 0,0933 & $<0,0001$ \\
\hline $\mathrm{C}$ & 0,0995 & 0,7182 & 0,0284 & 0,1868 & 0,0316 & $<0,0001$ & 0,0739 & $<0,0001$ & 0,0538 & 0,1300 \\
\hline D & 0,6332 & 0,3323 & 0,3261 & 0,0249 & $<0,0001$ & $<0,0001$ & $<0,0001$ & $<0,0001$ & 0,0105 & 0,0002 \\
\hline$E$ & 0,5668 & 0,5633 & 0,7438 & $<0,0001$ & $<0,0001$ & $<0,0001$ & 0,0226 & 0,0009 & 0,0001 & 0,0252 \\
\hline
\end{tabular}

${ }^{a}$ Masculin, ${ }^{b}$ Feminine

Table 4: Principal component analysis of all attributes and samples stratified by gender

\begin{tabular}{|c|c|c|c|c|c|c|c|c|c|c|c|c|c|c|c|c|c|c|c|c|}
\hline \multirow{3}{*}{$\begin{array}{l}\text { Code } \\
\text { Gender }\end{array}$} & \multicolumn{4}{|c|}{ A } & \multicolumn{4}{|c|}{ B } & \multicolumn{4}{|c|}{ C } & \multicolumn{4}{|c|}{ D } & \multicolumn{4}{|c|}{$E$} \\
\hline & \multicolumn{2}{|c|}{$\mathbf{M}^{\mathbf{a}}$} & \multicolumn{2}{|c|}{$F^{b}$} & \multicolumn{2}{|c|}{ M } & \multicolumn{2}{|c|}{$\mathbf{F}$} & \multicolumn{2}{|c|}{ M } & \multicolumn{2}{|c|}{$\mathbf{F}$} & \multicolumn{3}{|c|}{ M } & \multirow{2}{*}{$\begin{array}{c}F \\
F 1\end{array}$} & \multicolumn{2}{|c|}{ M } & \multicolumn{2}{|r|}{$\mathbf{F}$} \\
\hline & F1c & $\mathrm{F}^{\mathrm{d}}$ & F1 & F2 & F1 & F2 & F1 & F2 & F1 & F2 & F1 & F2 & F1 & F2 & F3 & & F1 & F2 & F1 & F2 \\
\hline Color & 0,32 & 0,19 & 0,39 & 0,70 & 0,71 & $-0,32$ & 0,20 & 0,68 & 0,45 & 0,74 & $-0,14$ & 0,76 & $-0,13$ & 0,87 & 0,20 & 0,42 & 0,20 & 0,57 & $-0,01$ & 0,79 \\
\hline Odor & 0,56 & $-0,51$ & 0,63 & 0,13 & 0,50 & 0,41 & 0,52 & 0,61 & 0,61 & 0,40 & 0,53 & 0,22 & 0,31 & 0,08 & 0,87 & 0,59 & 0,46 & $-0,67$ & 0,48 & $-0,40$ \\
\hline Flavor & 0,80 & 0,15 & 0,80 & $-0,25$ & 0,72 & $-0,09$ & 0,78 & $-0,23$ & 0,76 & $-0,42$ & 0,83 & 0,18 & 0,81 & 0,02 & $-0,05$ & 0,76 & 0,78 & $-0,07$ & 0,78 & 0,22 \\
\hline Sweetness & 0,48 & 0,75 & 0,73 & 0,16 & 0,48 & 0,10 & 0,62 & $-0,51$ & 0,71 & $-0,46$ & 0,76 & $-0,20$ & 0,85 & $-0,18$ & $-0,03$ & 0,65 & 0,63 & 0,55 & 0,69 & 0,33 \\
\hline Texture & 0,61 & $-0,43$ & 0,38 & $-0,70$ & 0,04 & 0,89 & 0,67 & 0,07 & 0,58 & 0,11 & $-0,01$ & 0,69 & 0,40 & 0,55 & $-0,45$ & 0,59 & 0,70 & $-0,14$ & 0,70 & $-0,30$ \\
\hline Proportion ${ }^{e}$ & 0,33 & 0,54 & 0,37 & 0,58 & 0,30 & 0,51 & 0,34 & 0,57 & 0,39 & 0,62 & 0,31 & 0,54 & 0,37 & 0,57 & 0,75 & 1,00 & 0,35 & 0,56 & 0,35 & 0,56 \\
\hline
\end{tabular}

${ }^{a}$ Masculin. ${ }^{b}$ Feminine. ${ }^{\mathrm{c}}$ Factor 1 , ${ }^{\mathrm{d}}$ Factor 2. ${ }^{\mathrm{e}}$ Cumulative proportion

Table 5: Multivariate analysis of variance (MANOVA) of acceptance attributes stratified by gender and juices

\begin{tabular}{lcc} 
& \multicolumn{2}{c}{$p$ value } \\
\cline { 2 - 3 } & Gender & Juices \\
\hline Wilks' lambda & 0.33 & $<0.0001$ \\
Pillai's trace & 0.33 & $<0.0001$ \\
Hotelling-Lawley trace & 0.33 & $<0.0001$ \\
Roy's greatest root & 0.33 & $<0.0001$ \\
\hline
\end{tabular}

Table 6: Comparative analysis of acceptance attributes in each juice

\begin{tabular}{llllll} 
Code & Color & Odor & Flavor & sweetness & Texture \\
\hline A & ab & b & b & c & a \\
B & ab & a & a & a & a \\
C & b & ab & a & ab & ab \\
D & a & ab & a & ab & a \\
E & a & b & b & b & b \\
\hline
\end{tabular}

The same letters within each column indicate no significant statistically difference $(p>0.05)$, Tukey's post-hoc test

\section{Total flavonoids content}

Table 7 shows the total content of flavonoids of the different juices. Flavonoids content in juices A, C and E did not show differences between them but they showed differences in comparison with juices B and D (Table 7).

Juices $\mathrm{B}$ and $\mathrm{D}$ showed the highest total flavonoids content with values of 38.00 and 33.02 catechin equivalents/L, respectively, and they didn't show significant differences between them (Table 7)

\section{Total carotenoids content}

Table 7 shows the carotenoid content of the five juices. Juices A and B showed the highest content of carotenoids corresponding to 12.76 and $15.48 \mathrm{mg} \beta$-carotene/L, respectively, and it didn't show significant differences between them, however it decreased in juice C. Juice E showed the lowest value for carotenoids corresponding to $10.51 \mathrm{mg} \beta$-carotene/L but did not show significant differences when compared to juices $\mathrm{C}$ and $\mathrm{D}$; therefore, the carotenoid content decreased between 8 and 30 days at $-20^{\circ} \mathrm{C}$, afterwards the carotenoid content increased.

\section{$\mathrm{DPPH} \bullet$ assay}

The DPPH $\bullet$ anti-radical efficiency values of juices analyzed in this study are presented in Fig. 3a. An increase in antioxidant activity was observed in juices after 8 days of storage and then it remained stable.

Juice B showed the highest radical scavenging activity against DPPH• $(1232.83 \mu \mathrm{mol}$ Trolox/L) and it showed significant differences to juices A, D and E. Juice A showed the lowest value for scavenging activity against DPPH radical (836.79 $\mu \mathrm{mol}$ Trolox/L); however, it did not show significant differences with juices $\mathrm{D}$ and $\mathrm{E}$.

\section{ABTS $^{\bullet+}$ assay}

The scavenging activity of mango juice against ABTS radical was determined using the $\mathrm{ABTS}^{*+}$ assay. An increase in $\mathrm{ABTS}^{-+}$values was observed in juices after 8 days of storage and then they remained stable. Juice $\mathrm{B}$ showed the highest value in the $\mathrm{ABTS}^{++}$assay corresponding to 1704.57 $\mu \mathrm{mol}$ Trolox/L and showed significant differences with all juices except with juice C. Juices A, D and E showed similar radical scavenging activity against ABTS radical within a range of $1358.79-1452.92 \mu \mathrm{mol}$ Trolox/L and they didn't show significant differences between them (Fig. 3b). 
Table 7: Changes in total flavonoids, carotenoids and polyphenols in juice prepared with mango stored at $-20^{\circ} \mathrm{C}$ during different days

\begin{tabular}{lccc}
\hline Code & Total phenolics (GAE/L) & Total carotenoids (mg $\beta$-carotene/L) & Total flavonoids (mg catechin equivalents/L) \\
\hline A & $155.4 \pm 14.1^{\mathrm{a}}$ & $12.7 \pm 0.8^{\mathrm{ab}}$ & $15.1 \pm 0.3^{\mathrm{b}}$ \\
$\mathrm{B}$ & $145.6 \pm 3.8^{\mathrm{a}}$ & $15.4 \pm 3.0^{\mathrm{a}}$ & $38.0 \pm 3.0^{\mathrm{a}}$ \\
$\mathrm{C}$ & $131.0 \pm 4.8^{\mathrm{a}}$ & $10.0 \pm 0.4^{\mathrm{c}}$ & $22.6 \pm 2.2^{\mathrm{b}}$ \\
$\mathrm{D}$ & $124.3 \pm 9.3^{\mathrm{a}}$ & $12.4 \pm 0.7^{\mathrm{bc}}$ & $33.0 \pm 1.4^{\mathrm{a}}$ \\
E & $124.3 \pm 13.7^{\mathrm{a}}$ & $10.5 \pm 0.5^{\mathrm{bc}}$ & $16.8 \pm 1.5^{\mathrm{b}}$
\end{tabular}

Values are the means \pm standard deviation of three replicates, the same small letters indicate not significant statistically difference $(p>0.05)$

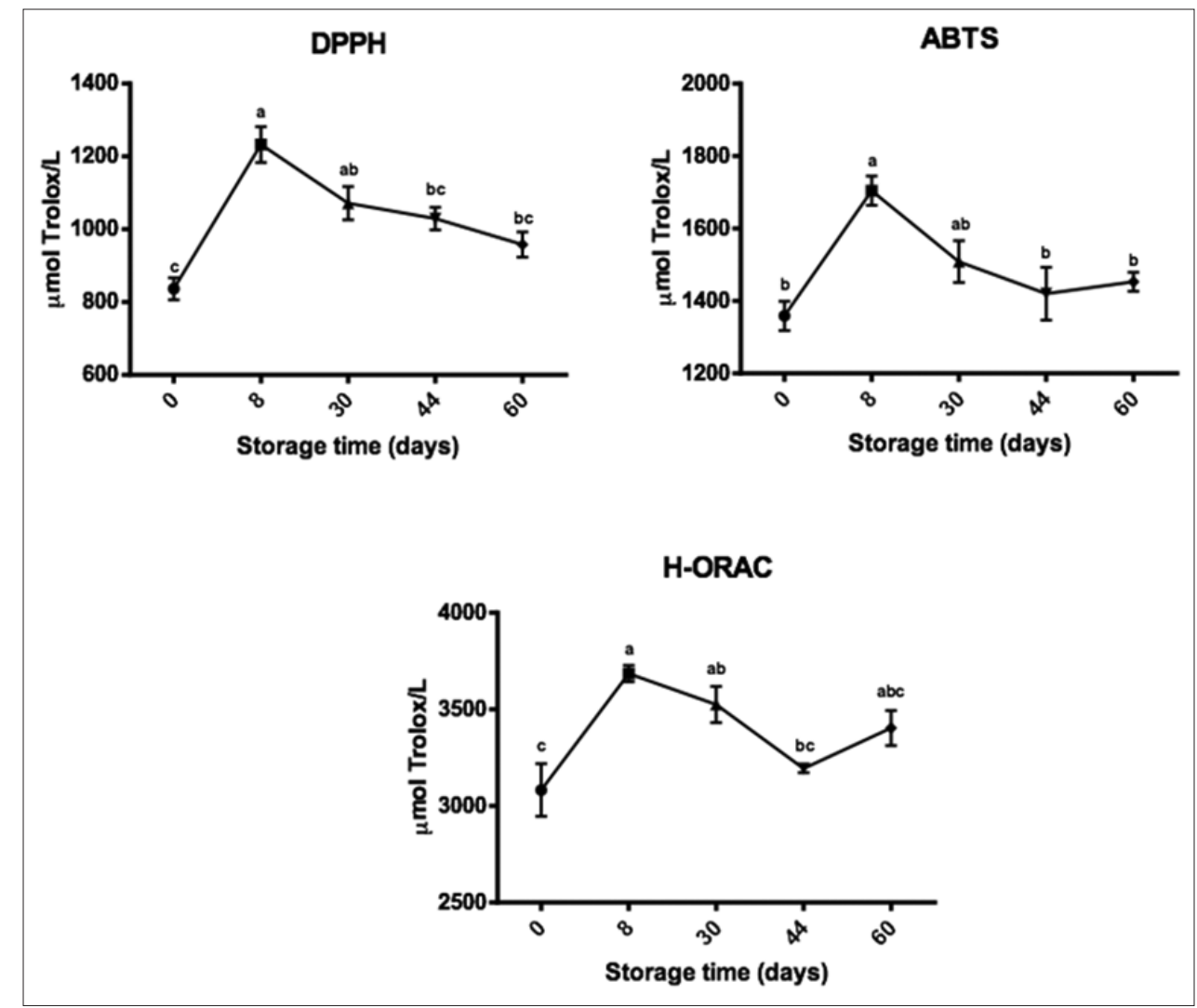

Fig 3. Influence of storage time of mango pulp at $-20^{\circ} \mathrm{C}$ in antioxidant activity.

\section{Hydrophilic ORAC assay}

Antioxidant capacity was measured by hydrophilic ORAC assay. The ORAC values increased after 8 days of storage and the values in juices $\mathrm{B}, \mathrm{C}$ and $\mathrm{E}$ were very similar and they didn't show significant differences between them. Juice A showed the lowest ORAC value corresponding to $3082.01 \mu \mathrm{mol}$ Trolox/L; however, it did not show significant differences in comparison with juices $\mathrm{D}$ and E (Fig. 3c).

\section{DISCUSSION}

This is the first study about the changes on sensory characteristics, antioxidant activity flavonoids, carotenoids and polyphenols content of a juice prepared with ripe mango cv. Azúcar at different storage time at $-20^{\circ} \mathrm{C}$.
Physico-chemical characteristics were similar between the juices except for percentage of total carbohydrates and calories (Kcal) which shown a variation due to the different amount of sucrose used in the preparation of the juices; therefore, juice B had the highest amount of sucrose and it showed the highest percentage of carbohydrates and calories. However, the total calories and carbohydrates in all juices were lower than those reported in a previous study about mango nectar (cv. Azúcar) freshly prepared in our laboratory which showed $81.5 \mathrm{Kcal}$ and $20.3 \%$ of carbohydrates; this is important considering the tendency of consumers to drink fruit beverages with low calorie content (Cardello and Wolfson, 2013).

The sensory analysis showed that acceptance of the juice was similar through 60 days of pulp storage, moreover it 
showed that juice $\mathrm{A}$ had the lowest overall acceptability in both genders and all age groups $(89.6 \%)$, this could be due to its lack of sweetness which was the attribute with the lowest acceptance and also because the panelists expressed that this nectar lacked sweetness. The acceptance of all juices was related to sweetness and flavor for both genders so these attributes will be important to consider for the production of this juice.

We carried out a principal component analysis and it showed that the perception of sensory attributes was better in women considering that they identified more attributes than men. The results of MANOVA indicate that the perception of sensory attributes wasn't different between men and women, and this was consistent with a previous study with freshly prepared mango nectar (cv. Azúcar). On the contrary, the perception of attributes was statistically different between juices, especially flavor but the perception of all attributes was similar for juices B, C and $\mathrm{D}$ except for color perception of all attributes among juices $\mathrm{B}, \mathrm{C}$ and $\mathrm{D}$ except for color.

In this study, we also determined the effect of storage time on polyphenols, flavonoids and carotenoids total content. Carotenoids content began to decrease after 8 days of storage of mango pulp at $-20^{\circ} \mathrm{C}$ which is consistent with a previous study that found a decreased in $\beta$-carotene in ripe mango (cvs. Lippens, Palmer and Smith) slices from Canary Islands stored at $-18^{\circ} \mathrm{C}$ during 120 days (Marin et al., 1992); carotenoids can be degraded by light, so this could be another factor that could explain the decrease of its content considering that juices were not completely protected from light during storage (Boon et al., 2010). Flavonoids content also showed a slight variation among different juices which can be due to pasteurization process considering that high temperatures have shown to induce degradation of these compounds (Sanchez et al., 2014; Lafuente et al., 2011).

Although the total phenolic content showed a slightly decrease during the storage time for mango pulp at $-20^{\circ} \mathrm{C}$ but it didn't show significant differences among juices, this could be due to inactivation by high temperature of polyphenol oxidases which catalyzes the oxidation of phenolic compounds; this is important considering that polyphenols have shown potent antioxidant activity in different studies (Pandey and Rizvi, 2009). Polyphenols content observed in this study was lower compared with other fruits such as Satsuma mandarin whose juice shown polyphenols content of $750.3 \mathrm{mg}$ gallic acid/L (Kelebek and Selli, 2014).

The antioxidant capacity was measured with three different methods in order to evaluate different antioxidant action mechanisms, considering $\mathrm{ABTS}^{\bullet+}$ and $\mathrm{DPPH} \bullet$ are reduced by either one electron transfer (SET) or hydrogen atom transfer (HAT) (Schaich et al., 2015); on the other hand ORAC assay is based in HAT mechanism (Schaich et al., 2015). Measures the antioxidant capacity of hydrophilic antioxidants. According to the solvent used in this study ABTS $^{*+}$ measured antioxidant activity of hydrophilic antioxidants too (Robles-Sanchez et al., 2009; Re et al., 1999), such as ascorbic acid and phenolic compounds, meanwhile $\mathrm{DPPH} \cdot$ measures hydrophilic and in some degree lipophilic antioxidants considering the solvent used in this assay. Also, the use of different methods to evaluate antioxidant capacity is necessary because there is not a single method which could give a complete information about different antioxidant mechanisms of fruits (RoblesSanchez et al., 2009).

The antioxidant capacity might be influenced by flavonoids such quercetin and catechin which are the main flavonoids present in mango according to USDA (United States Department of Agriculture) and they have shown antioxidant activity in vitro and in vivo, respectively (Saw et al., 2014; Yonekura et al., 2016). Phenolic acids such as gallic acid has been previously identified in mango cultivar Azúcar (Corrales-Bernal et al., 2014b), and it also has shown antioxidant activity in vitro (Naksuriya and Okonogi, 2015).

\section{CONCLUSION}

In this study, we prepared a mango juice with low calorie content, high content of fruit and without artificial colorants. We found that perception of its sensory attributes remained similar in juices prepared from mango stored up to 44 days; besides, the antioxidant activity was higher between 8 and 30 days of storage at $-20^{\circ} \mathrm{C}$ and the polyphenols content remained constant at the different storage time; therefore, a mango (cv. Azucar) juice could be prepared with peeled and ripe mango stored at $-20^{\circ} \mathrm{C}$ up to 30 days to achieve the maximum antioxidant activity without altering its sensory properties and it could be an alternative to increase consumption of fruits in order to prevent chronic diseases (Da Silva et al., 2014).

\section{ACKNOWLEDGMENTS}

Maria Bibiana Zapata Londoño is the recipient of a doctoral scholarship from the Francisco José Caldas Institute for the Development of Science and Technology (COLCIENCIAS). This work was supported by "Estrategia de Sostenibilidad 2014-2015" from Universidad de Antioquia (Colombia), and Universidad Nacional de Colombia (Medellín). 


\section{Author contributions}

M.B.Z.L: She performed all the experiments, analyzed the results, and prepared the manuscript. D.C: She prepared the juice and she participated in sensorial analysis. A.F.A.A and B.A.R: they performed and analyzed the antioxidant capacity and juice composition. M.E.M.C: She designed experiments, analyzed results and improved the paper. L.F.R.B: He advised the statistical analyses.

\section{REFERENCES}

Association of Official Analytical Chemists. 2016. Official Methods of Analysis, $20^{\text {th }}$ ed. Association of Official Analytical Chemists, Arlington, VA.

Bagchi, D., M. Bagchi, S. J. Stohs, D. K. Das, S. D. Ray, C. A. Kuszynski, S. S. Joshi and H. G. Pruess. 2000. Free radicals and grape seed proanthocyanidin extract: Importance in human health and disease prevention. Toxicology. 148(2-3): 187-197.

Biswas, A. K., J. Sahoo and M. K. Chatli. 2011. A simple UV-Vis spectro-photometric method for determination of $\beta$-carotene content in raw carrot, sweet potato and supplemented chicken meat nuggets. Food Sci. Technol. 44(8): 1809-1813.

Boon, C. S., D. J. McClements, J. Weiss and E. A. Decker. 2010. Factors influencing the chemical stability of carotenoids in foods. Crit. Rev. Food Sci. Nutr. 50(6): 515-532.

Brand-Williams, W., M. E. Cuvelier and C. Berset. 1995. Use of free radical method to evaluate antioxidant activity. LWT-Food Sci. Technol. 28(1): 25-30.

Cardello, H. and J. Wolfson. 2013. Interim Report: Lower-Calorie Foods and Beverages Drive Healthy Weight Commitment Foundation Companies' Sales Growth, Hudson Institute.

Corrales-Bernal, A., M. E. Maldonado, L. A. Urango, M. C. Franco and B. A. Rojano. 2014a. Mango de azúcar (Mangifera indica), variedad de Colombia: Características antioxidantes, nutricionales y sensoriales. Rev. Chil. Nutr. 41(3): 312-318.

Corrales-Bernal, A., L. A. Urango, B. Rojano and M. E. Maldonado. 2014b. In vitro and in vivo effects of mango pulp (Mangifera indica cv. Azucar) in colon carcinogenesis. Arch. Latinoam. Nutr. 64(1): 16-23.

Da Silva, P. P., R. C. Casemiro, R. R. Zillo, A. C. de Camargo, E. T. Prospero and M. H. Spoto. 2014. Sensory descriptive quantitative analysis of unpasteurized and pasteurized juçara pulp (Euterpe edulis) during long-term storage. Food Sci. Nutr. 2(4): 321-331.

Food and Drug Administration. 1998. Microbiological Methods \& Bacteriological Analytical Manual (BAM), $8^{\text {th }}$ ed. Food and Drug Administration, Washington, DC.

Hossain, M. A., M. M. Rana, Y. Kimura and H. A. Roslan. 2014. Changes in biochemical characteristics and activities of ripening associated enzymes in mango fruit during the storage at different temperatures. Biomed. Res. Int. 2014: 1-11.

Instituto Colombiano de Normas Técnicas y Certificación, ICONTEC (Ed). 2004. Norma Técnica Colombiana 5139: Frutas Frescas, Mangos Criollos, Especificaciones, El Institut, Bogotá, Colombia.

Instituto Colombiano de Normas Técnicas y Certificación, ICONTEC (Ed.). 2007. Norma Técnica Colombiana 4458: Microbiología de Alimentos y de Alimentos Para Animales. Método Horizontal Para el Recuento de Coliformes o Escherichia coli o Ambos. Técnica de Recuento de Colonias Utilizando Medios Uorogénicos o Cromogénico, Instituto Colombiano de Normas
Técnicas y Certificación, Bogotá, Colombia.

Kaur, C. and H. C. Kapoor. 2001. Antioxidants in fruits and vegetables - The millennium's health. Int. J. Food Sci. Technol. 36(7): 703-725.

Kelebek, H. and S. Selli. 2014. Identification of phenolic compositions and the antioxidant capacity of Mandarin juices and wines. J. Food Sci. Technol. 51(6): 1094-1101.

Kim, Y., J. K. Brecht and S. T. Talcott. 2007. Antioxidant phytochemical and fruit quality changes in mango (Mangifera indica L.) Following hot water immersion and controlled atmosphere storage. Food Chem. 105(4): 1327-1334.

Krenek, K. A., R. C. Barnes and S. T. Talcott. 2014. Phytochemical composition and effects of commercial enzymes on the hydrolysis of gallic acid glycosides in mango (Mangifera indica L. cv. 'Keitt') pulp. J. Agric. Food Chem. 62(39): 9515-9521.

Lafuente, M. T., A. R. Ballester, J. Calejero and L. González-Candelas. 2011. Effect of high-temperature-conditioning treatments on quality, flavonoid composition and vitamin $\mathrm{C}$ of cold stored 'Fortune' mandarins. Food Chem. 128(4): 1080-1086.

Liu, F. X., R. Li, Y. Wang, X. Bi and X. Liao. 2014. Effects of high hydrostatic pressure and high-temperature short-time on mango nectars: Changes in microorganisms, acid invertase, 5-hydroxymethylfurfural, sugars, viscosity, and cloud. Innov. Food Sci. Emerg. Technol. 22: 22-30.

Ma, X., H. Wu, L. Liu, Q. Yao, S. Wang, R. Zhan, S. Xing and Y. Zhou. 2011. Polyphenolic compounds and antioxidant properties in mango fruits. Sci. Hortic. 129(1): 102-117.

Manthey, J. A. and P. Perkins-Veazie. 2009. Influences of harvest date and location on the levels of $\beta$-carotene, ascorbic acid, total phenols, the in vitro antioxidant capacity, and phenolic profiles of five commercial varieties of mango (Mangifera indica L.). J. Agric. Food Chem. 57(22): 10825-10830.

Marin, M. A., P. Cano and C. Fúster. 1992. Freezing preservation of four Spanish mango cultivars (Mangifera indica L.): Chemical and biochemical aspects. Z. Lebensm. Unters. Forsch. 194(6): 566-569.

Marinova, D., F. Ribarova and M. Atanassova. 2005. Total phenolics and total flavonoids in Bulgarian fruits and vegetables. J. Univ. Chem. Technol. Metall. 40(3): 255-260.

Naksuriya, O. and S. Okonogi. 2015. Comparison and combination effects on antioxidant power of curcumin with gallic acid, ascorbic acid, and xanthone. Drug Discov. Ther. 9(2): 136-141.

Ou, B., M. Hampsch-Woodill and R. Prior. 2001. Development and validation of an improved oxygen radical absorbance capacity assay using fluorescein as the fluorescent probe. J. Agric. Food Chem. 49: 4619-4626.

Pandey, K. B. and S. I. Rizvi. 2009. Plant polyphenols as dietary antioxidants in human health and disease. Oxid. Med. Cell. Longev. 2(5): 270-278.

Prior, R. L., X. L. Wu and K. Schaich. 2005. Standardized methods for the determination of antioxidant capacity and phenolics in foods and dietary supplements. J. Agric. Food Chem. 53(10): 4290-4302.

Puertas-Mejía, M. A., L. Gómez-Chabala, B. Rojano and J. A. SáezVega. 2005. In vitro antioxidant capacity of fractions from Piper peltatum L. Leaves. Rev. Cubana Plant Med. 14(2): 1-10.

Re, R., N. Pellegrini, A. Proteggente, A. Pannala, M. Yang and C. Rice-Evans. 1999. Antioxidant activity applying an improved ABTS radical cation decolorization assay. Free Radic. Biol. Med. 26(9-10): 1231-1237.

Renuka, B., S. G. Kulkarni, P. Vijayanand and S. G. Prapulla. 
2009. Fructooligosaccharide fortification of selected fruit juice beverages: Effect on the quality characteristics. Food Sci. Technol. 42(5): 1031-1033.

Robles-Sánchez, R. M., M. A. Islas-Osuna, H. Astiazarán-García, F. A. Vázquez-Ortiz, O. Martín-Belloso, S. Gorinstein and G. A. González-Aguilar. 2009. Quality index, consumer acceptability, bioactive compounds, and antioxidant activity of fresh-cut "Ataulfo" mangoes (Mangifera indica L.) as affected by low-temperature storage. J. Food Sci. 74(3): S126-S134.

Romero, M., B. Rojano, J. Mella-Raipán, C. D. Pessoa-Mahana, E. Lissi and C. López-Alarcón. 2010. Antioxidant capacity of pure compounds and complex mixtures evaluated by the ORACpyrogallol red assay in the presence of Triton X-100 micelles. Molecules. 15(9): 6152-6167.

Sánchez, C., A. B. Baranda and I. M. Marañón. 2014. The effect of high pressure and high temperature processing on carotenoids and chlorophylls content in some vegetables. Food Chem. 163: 37-45.

Saw, C. L., Y. Guo, A. Y. Yang, X. Paredes-Gonzalez, C. Ramirez, D. Pung and A. N. Kong. 2014. The berry constituents quercetin, kaempferol, and pterostilbene synergistically attenuate reactive oxygen species: Involvement of the Nrf2-ARE signaling pathway. Food Chem. Toxicol. 72: 303-311.

Schaich, K. M., X. Tian and J. Xie. 2015. Hurdles and pitfalls in measuring antioxidant efficacy: A critical evaluation of ABTS DPPH, and ORAC assays. J. Funct. Foods. 14: 111-125.

Yonekura, L., C. A. Martins, G. R. Sampaio, M. P. Monteiro, L. A. César, B. M. Mioto, C. S. Mori, T. M. Mendes, M. L. Ribeiro, D. P. Arçari and E. A. Torres. 2016. Bioavailability of catechins from guaraná (Paullinia cupana) and its effect on antioxidant enzymes and other oxidative stress markers in healthy human subjects. Food. Funct. 7(7): 2970-2978. 